\title{
Plasma lidocaine concentrations are higher in twin compared to singleton newborns following epidural anesthesia for Cesarean delivery
}

\author{
[Les concentrations plasmatiques de lidocaïne sont plus élevées chez les nouveau-nés jumeaux, \\ comparés au nouveau-né unique, à la suite d'une anesthésie épidurale pour césarienne]
}

Manuel C. Vallejo MD, Sivam Ramanathan MD

\begin{abstract}
Purpose: This study compares plasma lidocaine concentrations in 16-sets of twin neonates to 16-singleton neonates all of whom were delivered by Cesarean section under lumbar epidural anesthesia (LEA).
\end{abstract}

Methods: Lidocaine I.5\% with epinephrine $5 \mu \mathrm{g} \cdot \mathrm{mL}^{-1}$ was used for activation of LEA. Upon delivery plasma lidocaine concentrations were measured from the maternal vein (MV), neonatal umbilical vein (UV) and umbilical artery (UA) using TDx fluorescence polarization immunoassay.

Results: MV lidocaine concentrations were similar in both twin and singleton mothers. Both mean lidocaine UV and UA levels were $35 \%$ higher in twin A (first-delivered) compared to the singleton neonate, $(P<0.01$, t test). Similarly, twin B mean UV and UA lidocaine levels were $35 \%$ and $53 \%$ higher than the singleton value ( $P$ $<0.0 \mathrm{I}$ ). Mean UV and UA lidocaine fetal/maternal ratios in both twins were at least I $8 \%$ higher than the singleton value $(P<0.05)$.

Conclusion: Even though there were no differences in neonatal outcome, a potential does exist for high plasma lidocaine concentrations in twin fetuses, suggesting that the total maternal dose of lidocaine must be regulated carefully.

Objectif : Comparer les concentrations plasmatiques de lidocaïne chez 16 paires de nouveau-nés jumeaux et chez 16 nouveau-nés uniques, tous nés par césarienne sous anesthésie épidurale lombaire (AEL).

Méthode : L'activation de l'AE L a été réalisée avec de la lidocaïne à I,5\% et $5 \mu \mathrm{g} \cdot \mathrm{mL}^{-1}$ d'épinéphrine. À l'accouchement, on a mesuré les concentrations plasmatiques de lidocaïne à partir d'échantillons de la veine maternelle (VM), de la veine ombilicale du nouveau-né (VO) et de l'artère ombilicale $(\mathrm{AO})$ en utilisant l'immunodosage à polarisation de fluorescence TDx.
Résultats : Les concentrations de lidocaïne de la VM étaient comparables chez les mères de jumeaux et d'enfant unique. Les niveaux de lidocaïne de la VO et de l'AO ont été plus élevés de $35 \%$ chez les jumeaux $A$ (premier né) comparés aux nouveau-nés uniques $(P<$ 0,01 , test $t$ ). De même, la moyenne des niveaux de lidocaïne de la VO et de l'AO chez les jumeaux B a été de $35 \%$ et de $53 \%$ plus élevée que chez les enfants uniques $(P<0,01)$. Les ratios moyens de lidocaiine fotale/maternelle des VO et $A O$ ont été d'au moins $18 \%$ plus élevés chez les deux jumeaux que chez les enfants uniques $(P<0,05)$.

Conclusion : Même si l'évolution néonatale ne présente pas de différence, il y a une possibilité de concentrations plasmatiques de lidocaïne élevées chez les fœtus jumeaux, ce qui incite à régler minutieusement la dose totale de lidocaïne maternelle.

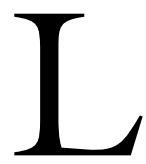
OCAL anesthetics are rapidly absorbed from the epidural space into the maternal systemic circulation and transferred to the fetus via the uteroplacental circulation. ${ }^{1}$ Uteroplacental transfer of local anesthetics depends on multiple factors including: maternal drug concentration, volume of distribution, maternal cardiac output and uterine blood flow, amount of placental surface available for drug transfer, $\mathrm{pKa}$, protein binding, maternal and fetal blood $\mathrm{pH}$, and the ratio of ionized and unionized drug fractions. ${ }^{1,2}$

Multiple gestation causes additional changes in maternal cardiac output and blood volume compared to singleton gestation. The purpose of this study is to determine the effect of twin pregnancy on maternal and fetal lidocaine levels compared to a singleton pregnancy.

From the Department of Anesthesiology, Magee-Womens Hospital, University of Pittsburgh, Pittsburgh, Pennsylvania, USA.

Address correspondence to: Dr. Manuel C. Vallejo, Department of Anesthesiology, Magee-Womens Hospital, University of Pittsburgh,

300 Halket Street, Pittsburgh, PA 15213, USA. Phone: 412-641-4260; Fax: 412-641-4766; E-mail: vallejomc@anes.upmc.edu

Accepted for publication March 7, 2002.

Revision accepted May 27, 2002. 
TABLE I Demographic data, total lidocaine dose, gestational age, and neonatal data

\begin{tabular}{|c|c|c|c|c|c|}
\hline & Singleton & $\operatorname{Twin} A$ & Twins & $\operatorname{Twin} B$ & $P$ \\
\hline Age (yrs) & $26.0 \pm 5.0$ & & $25.0 \pm 6.0$ & & 0.612 \\
\hline Height $(\mathrm{cm})$ & $161.0 \pm 7.0$ & & $160.0 \pm 2.0$ & & 0.587 \\
\hline Weight (kg) & $73.0 \pm 2.0$ & & $79.0 \pm 7.1$ * & & 0.003 \\
\hline Gestational age (weeks) & $38.0 \pm 3.0$ & & $37.0 \pm 3.0$ & & 0.353 \\
\hline Lidocaine dose (mg) & $365.0 \pm 10.0$ & & $372.0 \pm 14.0$ & & 0.114 \\
\hline Incision delivery time ( $\mathrm{sec}$ ) & $91.0 \pm 10.0$ & $100.0 \pm 15.0$ & & $199.0 \pm 18.0 * \#$ & 0.000 \\
\hline Birth weight (g) & $3832 \pm 289$ & $3040 \pm 153^{*}$ & & $2741 \pm 441 * \#$ & 0.000 \\
\hline Apgar $1 \mathrm{~min}$ & $8.0 \pm 6.0$ & $8.3 \pm 0.4$ & & $8.5 \pm 0.5$ & 0.920 \\
\hline Apgar $5 \mathrm{~min}$ & $9.0 \pm 0.5$ & $9.0 \pm 0.42$ & & $9.0 \pm 0.47$ & 1.000 \\
\hline
\end{tabular}

Data are mean \pm SD of 16 observations made in patients with singleton or twin pregnancies. * Significantly different from singleton gestation; \# Significantly different from twin A.

TABLE II Blood gas tensions in maternal artery, neonatal UV and UA at delivery

\begin{tabular}{|c|c|c|c|c|}
\hline & $\mathrm{PO}_{2}(m m H g)$ & $\mathrm{PCO}_{2}(\mathrm{mmHg})$ & $p H$ & Base excess $\left(\mathrm{mmol} \cdot \mathrm{L}^{-1}\right)$ \\
\hline Maternal (singleton) & $242.0 \pm 8.0$ & $31.0 \pm 2.0$ & $7.42 \pm 0.01$ & $-6.0 \pm 1.0$ \\
\hline UV (singleton) & $30.0 \pm 7.0$ & $42.0 \pm 4.6$ & $7.35 \pm 0.05$ & $-1.9 \pm 2.3$ \\
\hline UA (singleton) & $14.0 \pm 3.8$ & $50.8 \pm 4.8$ & $7.31 \pm 0.05$ & $-0.9 \pm 2.6$ \\
\hline Maternal (twin) & $235.0 \pm 8.0 *$ & $30.0 \pm 2.0$ & $7.43 \pm 0.01$ & $-5.0 \pm 2.0$ \\
\hline $\mathrm{UV}($ twin $\mathrm{A})$ & $32.0 \pm 5.0$ & $38.0 \pm 3.0$ * & $7.37 \pm 0.03$ & $-2.9 \pm 2.0$ \\
\hline UA (twin A) & $18.0 \pm 3.3^{*}$ & $43.0 \pm 5.0^{*}$ & $7.34 \pm 0.04$ & $-2.3 \pm 1.7$ \\
\hline UV (twin B) & $26.0 \pm 6.5 \#$ & $41.0 \pm 4.3 \#$ & $7.35 \pm 0.02 \#$ & $-2.3 \pm 1.9$ \\
\hline $\mathrm{UA}$ (twin $\mathrm{B}$ ) & $17.0 \pm 3.7^{*}$ & $47.0 \pm 4.2 * \#$ & $7.31 \pm 0.04 \#$ & $-2.3 \pm 1.9$ \\
\hline
\end{tabular}

Data are mean $\pm \mathrm{SD}(n=16)$. UV = umbilical vein; UA = umbilical artery; * Significantly different from singleton gestation; \#Significantly different from twin A.

\section{Methods}

The local Institutional Review Board approved the study protocol and patients gave informed written and verbal consent. Sixteen parturients with a twin pregnancy and 16 control parturients with a singleton pregnancy who agreed to participate in the study were sequentially included over a six-month time period. All patients were scheduled for elective Cesarean delivery and were free from preexisting medical or pregnancyinduced complications. Patients received $1000 \mathrm{~mL}$ of Ringer's lactate intravenously prior to induction of epidural anesthesia. At the $\mathrm{L}_{3}-\mathrm{L}_{4}$ vertebral interspace, an epidural catheter was inserted $4 \mathrm{~cm}$ into the epidural space using a loss of resistance technique. Following a test dose of $3 \mathrm{~mL}$ of lidocaine $1.5 \%$ with $1: 200,000$ epinephrine to rule out intrathecal or venous catheter placement, 5-mL incremental injections of the same anesthetic were given to reach a T4 dermatome level. All patients received $6 \mathrm{~L} \cdot \mathrm{min}^{-1}$ of oxygen via a disposable oxygen mask with left uterine displacement. The Nellcor pulse oximeter (Nellcor Inc., Hayward CA, USA) was used to measure continuous maternal oxygen saturation $\left(\mathrm{SaO}_{2}\right)$. External upper extremity maternal blood pressure was measured and recorded every two minutes using Dinamap ${ }^{\mathrm{TM}}$ (Critikon Inc., Tampa, FL, USA). Hypotension (systolic blood pressure < 100 $\mathrm{mmHg}$ ) was treated with $5-\mathrm{mg}$ increments of ephedrine intravenously.

At delivery, the maternal radial artery was sampled for blood gas analysis with a single stick using a \#25 G needle. Maternal venous (MV) blood was collected from the antecubital vein and heparin was added as an anticoagulant. The specimen was centrifuged, plasma isolated and frozen at $-20^{\circ} \mathrm{C}$ until analyzed for total plasma lidocaine concentration. Additionally, neonatal umbilical vein (UV) and umbilical artery (UA) samples were collected in heparin from the segment of a doubly clamped umbilical cord for measurement of blood $\mathrm{pH}$, gas tensions and lidocaine levels. The umbilical cord of the first born (twin A) and the second born (twin B) were identified by placing one and two clamps on the respective umbilical cord. Neonatal Apgar scores and birth weights were also recorded.

Plasma lidocaine levels were measured using the TDx automated immunoassay method (Abbot Diagnostic, Eden Prairie, MN, USA) with a lower 
detection limit of $0.1 \mu \mathrm{g} \cdot \mathrm{mL}^{-1}$ and a cross-reactivity of $<0.05 \%$ to lidocaine metabolites. ${ }^{3-5}$ Compared to high pressure liquid chromatography, TDx immunoassay shows excellent correlation, with a reported correlation coefficient of 0.944 , a slope of 0.975 and an intercept of $0.096 .{ }^{5} \mathrm{Fetal} /$ maternal $(\mathrm{F} / \mathrm{M})$ lidocaine concentration ratios were calculated by dividing neonatal UV or UA lidocaine values by MV values for lidocaine.

\section{Statistical analysis}

Results were expressed as mean \pm SD. Values from twin A and/or twin B were compared with corresponding values from the singleton fetus using unpaired $t$ test. Values from twins were compared with each other using paired $t$ test. Data were analyzed using Statistica for Windows, version 5.1. (Statsoft, Tulsa, Oklahoma, USA). A $P<0.05$ was considered significant.

\section{Results}

Sixteen parturients with a twin pregnancy at $37 \pm 3$ weeks gestation and 16 parturients with a singleton pregnancy at $38 \pm 4$ weeks gestation were studied. No parturient who agreed to participate failed to complete the study. Table I presents demographic information, neonatal birth weight and Apgar scores. No significant differences existed in age, height, and gestational age between parturients carrying singleton and multiple gestations (Table I). However, compared to singleton parturients, twin parturients weighed more (Table I). Mean total dose of epidural lidocaine used to establish anesthesia for Cesarean section was not significantly different between the singleton and twin groups. Uterine incision to delivery time was shortest in the singleton delivery and longest in twin B (Table I). Both twin A and twin B had a smaller birth weight than the singleton newborn and twin $\mathrm{B}$ was significantly smaller than twin A (Table I). Both one-and five-minute Apgar scores were similar in singleton and twin newborns (Table I). All babies from both groups had a normal postnatal course.

Six parturients with a twin pregnancy $(37.5 \%)$ and five parturients with a singleton pregnancy $(31.3 \%)$ were treated for maternal hypotension (systolic blood pressure $<100 \mathrm{mmHg}$ ) with ephedrine $(P=\mathrm{NS})$. All twin gestations had a single placenta with two umbilical cords. Fourteen of the twin placentas were dichorionic and diaminiotic. Information as to the number of amnions and chorions in the remaining two twin placentas were not available.

MV plasma lidocaine concentrations were not significantly different from each other in both the twin

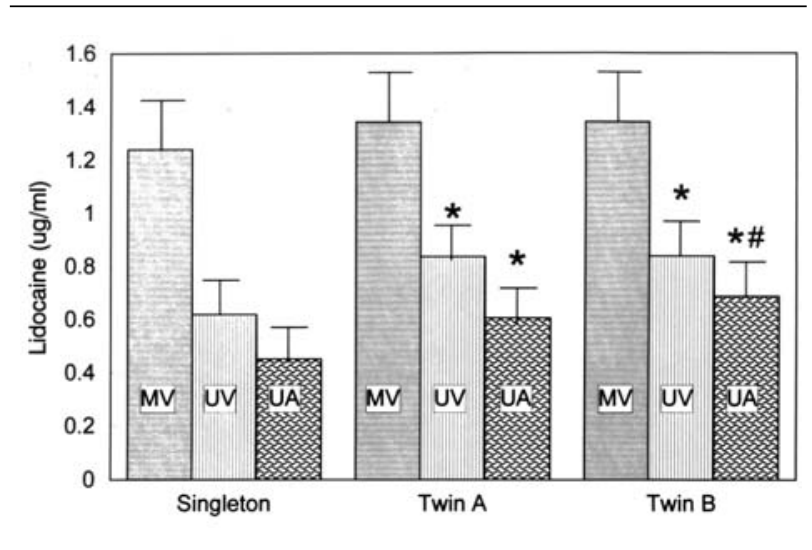

FIGURE 1 Plasma lidocaine concentration in singleton and twin neonates. $\mathrm{MV}=$ maternal vein; $\mathrm{UV}=$ neonatal umbilical vein; $\mathrm{UA}$ = neonatal umbilical artery; *Significantly different from the corresponding value in the singleton subjects; \#Significantly different from the corresponding value of twin A. For all statistical comparisons, $P$ values are $<0.01$.

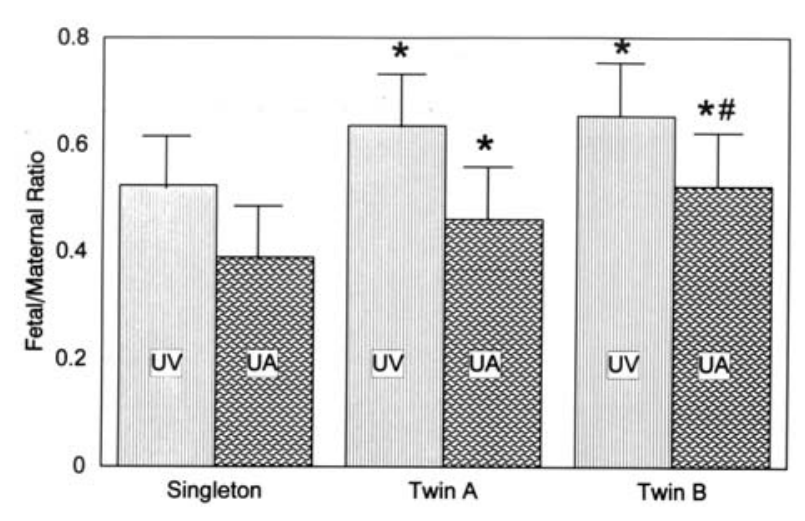

FIGURE $2 \mathrm{Fetal} /$ maternal plasma concentration ratio in the umbilical vein (UV) and umbilical artery (UA) in singleton and twin gestations. * Significantly different from the corresponding value in the singleton subjects. \#Significantly different from the corresponding value of twin A. For all statistical comparisons, $P$ values are $<0.05$.

and singleton groups (Figure 1). However, both UV and UA plasma lidocaine concentrations were significantly higher in both twins compared to the singleton neonate $(P<0.01$, Figure 1). Additionally, UA lidocaine concentration in twin $\mathrm{B}$ was significantly higher than in twin $\mathrm{A}(P<0.01$, Figure 1$)$. Regression analysis did not reveal correlation with respect to body mass index (BMI), UA and UV lidocaine concentrations. 
Both F/M UV and UA ratios were significantly higher in both twins compared to the singleton newborn. The UA blood $\mathrm{F} / \mathrm{M}$ ratio in twin $\mathrm{B}$ was significantly higher than twin $\mathrm{A}(P<0.05$, Figure 2$)$.

Table II presents maternal arterial blood gas tensions, neonatal UV and UA gas tensions and $\mathrm{pH}$ at delivery. No differences were noted in continuous maternal $\mathrm{SaO}_{2}$ saturation between groups. Maternal arterial $\mathrm{PCO}_{2}, \mathrm{pH}$ and base excess were not significantly different between the singleton and twin gestational groups (Table II). However, maternal arterial $\mathrm{PO}_{2}$ was slightly lower in twins compared to singleton parturients.

Compared to the singleton fetus, no differences were noted in twin umbilical arterial, and twin UV pH and base excess (Table II). However, umbilical arterial $\mathrm{PO}_{2}$ in both twins was higher than the singleton value. Likewise, umbilical arterial $\mathrm{PCO}_{2}$ in both twins was lower compared to the singleton (Table II).

\section{Discussion}

The degree of drug transfer across the placenta depends on: 1) maternal concentration of lidocaine; 2) maternal cardiac output and uterine blood flow; 3 ) placental surface available for transfer; 4) physicalchemical properties of the drug $(\mathrm{pKa}$, protein binding); and 5) maternal and fetal blood $\mathrm{pH}$, which determines the ratio between ionized and unionized fractions of lidocaine and blood $\mathrm{pH} .{ }^{1,2}$ Although lidocaine $\mathrm{F} / \mathrm{M}$ ratios are known for singleton human fetuses, ${ }^{6,7}$ no data are available for twin fetuses. Our results show there is increased fetal uptake of lidocaine in both twin fetuses compared to the singleton fetus.

The reason for increased fetal UV and umbilical arterial lidocaine uptake in twins in our study was not related to any difference in maternal vein concentration because maternal vein lidocaine levels were not significantly different between the singleton and twin groups. Additionally, there was no difference in mean total dose of epidural lidocaine to establish anesthesia for Cesarean section between both groups. Furthermore, the higher twin maternal body weight could not account for higher fetal lidocaine levels because there was no correlation with respect to BMI and UA and UV lidocaine concentrations using regression analysis.

Why would twin fetuses have higher plasma lidocaine concentrations? It is well known that both heart rate and stroke volume are increased in twin pregnancies, especially during the third trimester, leading to a significant increase in cardiac output and cardiac index compared to singleton pregnancies. ${ }^{8}$ Additionally, the normal increase in plasma volume is expanded even more so in twin pregnancies. ${ }^{9,10}$ Likewise, the increase in uterine blood flow is greater than a singleton pregnancy and the uteroplacental unit is larger. ${ }^{9}$ The two placentas in twin gestations can act as a parallel lowresistance circuit, causing a fall in systemic vascular resistance with increased blood flow. ${ }^{9}$ Morris et al. ${ }^{11}$ found the mean clearance time of $\mathrm{NaCl}$ from the uterine muscle of twin pregnancies was $50 \%$ longer than in singleton pregnancies. The increase in cardiac output, plasma volume, as well as uterine blood flow in twin pregnancy can enhance lidocaine delivery to the larger twin fetoplacental unit. Amide local anesthetics like lidocaine are highly protein bound which limits placental transfer. However, maternal total protein levels drop considerably in twin pregnancy compared to singleton. ${ }^{10}$ Kennedy et al. ${ }^{12}$ identified maternal and fetal protein binding and blood $\mathrm{pH}$ as fundamental factors controlling fetal lidocaine levels. The drop in total serum protein in twin pregnancy increases the amount of free lidocaine available to the fetus.

Another factor for increased lidocaine levels in twins may be related to birth weight. As noted in this study, twin fetuses are normally smaller than singleton fetuses. ${ }^{13}$ Smaller body weight is associated with a lower volume of distribution and hence higher plasma fetal drug levels. ${ }^{2}$ Additionally, differences in oxygenation between twins and singleton are due to fetal weight. ${ }^{14}$ The transfer of oxygen across the placenta is blood-flow limited and the placenta supplies about 8 $\mathrm{mL} \mathrm{O}_{2} \cdot \mathrm{min}^{-1} \cdot \mathrm{kg}^{-1}$ of fetal weight. ${ }^{14}$ In our study, mean singleton birth weight is greater than twin birth weight (Table II), which explains the lower singleton UA oxygen tension.

Vascular communications, which are more likely to occur in a monochorionic placenta, can affect the amount of drug reaching either of the twin fetuses and thus affects the plasma concentration of drugs that cross the placenta from the maternal circulation. None of our twin neonates had any evidence of twin-to-twin transfusion such as anemia or vascular overload. In addition, most of our patients with a twin pregnancy had a dichorionic placenta.

Birth order influences the blood-gas status of twins. ${ }^{15,16}$ Both Fuchi and Young noted substantial differences between twin $\mathrm{A}$ and twin $\mathrm{B}$ with respect to their oxygenation with conditions consistently favouring twin A. ${ }^{15,16}$ Young et al. ${ }^{16}$ attributed the poor outcome in twin B to reduced uterine size following the delivery of twin A with decreased intervillous blood flow, and alteration in the placental volume produced by clamping the umbilical cord of twin A. Our results confirm Young's results in that twin $\mathrm{B}$ had lower UV and $\mathrm{UA} \mathrm{pH}$ and $\mathrm{PO}_{2}$ and higher $\mathrm{PCO}_{2}$. The decreased 
blood $\mathrm{pH}$ in twin $\mathrm{B}$ may also have contributed to higher lidocaine uptake due to decreased protein binding and increased ion trapping. ${ }^{1,17}$

No differences were noted with respect to uterine incision to delivery times between singleton and twin A deliveries. However, twin B delivery time was significantly longer compared to both singleton and twin A delivery times. The prolonged time interval in delivery of twin B may have accentuated the higher lidocaine $\mathrm{F} / \mathrm{M}$ ratio in twin $\mathrm{B}$, but this is clearly not the only reason for the increased lidocaine $\mathrm{F} / \mathrm{M}$ levels in twins.

In conclusion, even though there were no clinical differences in neonatal outcome, it is important to realize that a potential does exist for high plasma lidocaine concentrations in twin fetuses and, therefore the total maternal dose of lidocaine must be carefully regulated. Further research is needed to assess local anesthetic concentrations in twin fetuses whose mothers receive continuous epidural infusion for prolonged periods of time for labour analgesia.

\section{References}

1 Biehl D, Shnider SM, Levinson G, Callender K.

Placental transfer of lidocaine: effects of fetal acidosis. Anesthesiology 1978; 48: 409-12.

2 Wilkinson GR. Pharmacokinetics: the dynamics of drug absorption, distribution, and elimination. In: Hardman JG, Limbird LE, Gilman AG (Eds.). The

Pharmacological Basis of Therapeutics, 10th ed. New York: McGraw-Hill, 2001: 3-29.

3 Caplan $\Upsilon H$, Levine B. Application of the Abbott TDx lidocaine, phenytoin, and phenobarbital assays to postmortem blood specimens. J Anal Toxicol 1988; 12: 265-7.

4 Sedman AJ, Molitoris BA, Nakata LM, Gal J. Therapeutic drug monitoring in patients with chronic renal failure: evaluation of the Abbott $\mathrm{TDx}^{\mathrm{TM}}$ drug assay system. Am J Nephrol 1986; 6: 132-34.

5 Ramanathan J, Bottorff M, Jeter JN, Khalil M, Sibai $B M$. The pharmacokinetics and maternal and neonatal effects of epidural lidocaine in preeclampsia. Anesth Analg 1986; 65: 120-6.

6 Abboud TK, David S, Nagappala S, et al. Maternal, fetal, and neonatal effects of lidocaine with and without epinephrine for epidural anesthesia in obstetrics. Anesth Analg 1984; 63: 973-9.

7 Abboud TK, Sarkis F, Blikian A, Varakian L, Earl S, Henriksen E. Lack of adverse neonatal neurobehavioral effects of lidocaine. Anesth Analg 1983; 62: 473-5.

8 Veille JC, Morton MJ, Burry KJ. Maternal cardiovascular adaptations to twin pregnancy. Am J Obstet Gynecol 1985; 153: 261-3.

9 Gardner MO, Wenstrom KD. Maternal adaptation. In:
Gall SA (Ed). Multiple Pregnancy and Delivery. St. Louis: Mosby-Year Book, Inc., 1996: 99-109.

10 MacGillivray I, Campbell D, Duffus GM. Maternal metabolic response to twin pregnancy in primigravidae. J Obstet Gynaecol Br Commonw 1971; 78: 530-4.

11 Morris N, Osborn SB, Wright HP. Effective circulation of the uterine wall in late pregnancy. Measured with $\mathrm{NaCl}$. Lancet $1955 ; 265$ : 323-5.

12 Kennedy RL, Bell JU, Miller RP, et al. Uptake and distribution of lidocaine in fetal lambs. Anesthesiology 1990; 72: 483-9.

13 Grothe $W$, Ruttgers $H$. Twin pregnancies: an 11-year review. Acta Genet Med Gemellol (Roma) 1985; 34: 49-58.

14 Longo LD. Respiration in the fetal-placental unit. In: Cowett RM (Ed.): Principles of Perinatal-Neonatal Metabolism. New York: Springer-Verlag, 1991: 304.

15 Fuchi I, Noda K. Twin umbilical cord blood gas values. Acta Genet Med Gemellol 1992; 41: 137-42.

16 Young BK, Suidan J, Antoine C, Silverman F, Lustig I, Wasserman J. Differences in twins: the importance of birth order. Am J Obstet Gynecol 1985; 151: 915-21.

17 Nancarrow C, Runciman WB, Mather LE, Upton RN, Plummer JL. The influence of acidosis on the distribution of lidocaine and bupivacaine into the myocardium and brain of the sheep. Anesth Analg 1987; 66: 925-35. 